Pragmatics 7:3.367-387

International Pragmatics Association

DOI: $10.1075 /$ prag.7.3.04tan

\title{
IN OTHER WORDS AND CONVERSATIONAL IMPLICATURE ${ }^{1}$
}

\author{
Hiroaki Tanaka
}

\section{Introduction}

In this paper, I will propose the hearer's implicature-interpretation process, which constrains the use of in other words (hereafter $I O W$ ) in English. I will distinguish between speaker's intended implicature and hearer's interpreted implicature. Speaker A may intend to implicate X, but Hearer B may fail to recognize such implicature, or may interpret some other implicatures. Even if Hearer B correctly interprets Speaker A's intention, B's interpretation depends largely on the context and/or background assumption. The use of $I O W$ is such a case. Quirk et al. (1972: 670, 1985: 653ff) formally call one usage of IOW "inferential function," though Ball (1986) uses the term rather informally. I will follow the formal use of inferential function for the sake of convenience.

Five points will be mentioned, particularly focussing on point (iv). Section 2 briefly refers to (i) the prototypical meaning of $I O W$, i.e., summarization, (ii) the derivational meaning of $I O W$, i.e., easier way of speaking, metaphorical way of saying something. And (iii) I will also discuss Blakemore's (1996) analysis of IOW as "higher level explicature" in Section 2, which subsumes $I O W$ under sentential adverbs such as regrettably and frankly. Section 3 discusses (iv) the inferential function of $I O W$ and the hearer's interpretation of the speaker's conversational implicature, and when and how the hearer fails to interpret correctly the speaker's intent. Finally, (v) IOW is compared with $s o$.

This paper suggests (a) that the distinction between (i-ii) and (iii) proves to be primary on the levels of lexical, functional meaning, which can be thought of as a "continuum" or "cline." (b) The distinction between the implicatures intended by the speaker and interpreted by the hearer is important on the level of pragmatics. This latter distinction is the focus of this paper.

The author's theoretical implications mostly rely on the Relevance Theoretic framework. However, since the aim of this paper is to ask whether deriving conversational implicature by the speaker and interpreting it by the hearer are the same, the inferential

\footnotetext{
${ }^{1}$ An earlier draft of this paper was originally presented at the $24^{\text {th }}$ annual meeting of the Linguistic Association of the Southwest (LASSO XXIV) in Las Cruces, New Mexico, October 1995. I am very grateful to Mary Jane Hurst (Texas Tech University) who chaired and many others who commented at the meeting. I also benefited from insightful comments from Tomoshichi Konishi, Tokumi Kodama, Shiro Wada, Seiji Uchida, Ichiro Akano and Kenji Kashino, and useful data from many members of the Linguist List supported by Texas A \& M. Thanks are also due to Donald W. Sturge for extensive stylistic suggestions. Of course, any oversights and misconceptions are my own.
} 
process which derives conversational implicature by Relevance Theory is not sufficient, but must be modified by "abductive" inferential process. This modification, which this paper also aims at, mainly focusses on the use of $I O W$.

\section{The function of $I O W$}

\subsection{The prototypical meaning IOW}

The prototypical meaning of $I O W$ is "summarization." $I O W$ proposes another way of saying what has just been said. The use of $I O W$ conveys that the utterance it prefaces provides 'other words' for what has just been said. Quite often, IOW reduces an argument to its simplest terms, making points very clear:

(1) a. Patrick works hard; in other words he's an excellent student. ${ }^{2}$

b. I shall argue that the meaning of so (and...) cannot be analyzed in terms of its contribution to the proposition expressed by the utterance that contains it but must be instead analyzed in terms of a constraint to the inferential computations that proposition may enter into - or in other words, its relevance. (from Blakemore (1988)) ${ }^{3}$

Mostly, IOW summarizes the content of the first clause, but sometimes expresses the exact literal meaning the first clause implies:

(2) Most of us who set out to do landscape painting refer most readily for our inspiration to the works of Constable and Turner, to the impressionists (both French and English), to pictures of the twentieth century and to the modern contemporary artists, in other words, the landscape paintings of the nineteenth and twentieth century. (from Word Bank of COBUILD on $C D-R O M)$

${ }^{2}$ The basic use of $I O W \mathrm{~m}$ is cited mostly from one person's utterance, in which case no implicature is drawn from the first clause. Most of the implicature drawing examples are cited from dialogue type utterances. Different utterance meaning do not shift abruptly from one category to another. Marginal examples are (16) and the following utterance by two persons.

(i) "What happened in yesterday's game?" "We were winning until the eighth inning, but you know our pitcher is only a rookie!" "Oh I see. In other words, you lost!"

In both cases, it is appropriate to say that the speaker who uses $I O W$ summarizes the previous utterance or utters the implicature the other person wanted to suggest. This vagueness depends on how much particular/contextually the implicature is hinted at by the first speaker and how well the second speaker can decode the utterance and process the interential system. In either case, the decoding/inferring system works well, directly or indirectly.

${ }^{3}$ Note that or co-occurs with $I O W$ when or functions as equalizer, signaling the same content as previous utterance. 


\subsection{The derivational function of $I O W$}

Derivationally, IOW is usually used to say things more easily:

(3) BOB: Cease! Desist!

BILL: In other words, you want me to stop?

Sometimes, summarizing something brings a metaphorical way of saying something. IOW in (4) is used to change a 'flash in the pan' into an easier and more understandable metaphorical way of saying:

(4) Putting fluoride into water has only temporary effect on children's health. It's a flash in the pan. In other words, it's papering over the crack. (from Ball (1986))

\subsection{Blakemore's (1996) "higher level explicature"}

Relevance Theory (Sperber and Wilson (1986); Wilson and Sperber (1993)) distinguishes the utterance levels into two: explicature and implicature.

Consider (5B) as a response to the question in (5A).

(5) A: Did you get invited to the conference?

B: $\quad$ They said my paper was too long. (Blakemore (1996))

(5B) is represented in two ways, i.e., (6a) and (6b). The assumption in (6a) is "explicature" obtained by "reference assignment," "disambiguation" and "enrichment," whereas the assumption in (6b) is "implicature" inferred from (6a) and bot are based on the context and the presumption that the utterance is "optimally relevant."

(6) a. The conference organizer said that the article submitted by the speaker was too long for the conference.

b. The speaker did not get invited to the conference.

The explicature in (6a) is the truth conditional content of (5B), or in other words proposition expressed by (5B). However, Relevance Theoretic notion of explicature, particularly in Wilson and Sperber (1993), is not always identified with the truth conditional content of the proposition. This is "higher level explicature," in which the proposition is subsumed into a higher-level illocutionary or attitudinal predicate, as in (7a) and ( $7 \mathrm{~b})$. The speaker of (5B) might have intended to utter his attitudinal predication in (7).

(7) a. The speaker of (5B) is telling the hearer that the conference organizers said that the paper was too long for the conference.

b. The speaker of $(5 \mathrm{~B})$ regrets that the conference organizers said that the paper was too long for the conference. (Blakemore (1996)) 
"Higher level explicature", in contrast with "explicature" in general, does not contribute to the truth conditional content of the proposition. For example, the truth of ( $7 b)$ does not depend on whether or not the speaker regrets the event, but rather the content of the sentence said by the conference organizer that the paper was too long. Thus, the analysis of sentential adverbs such as regrettably in (8) is also applied to "higher level explicature," which does not contribute to the truth conditions, i.e., "non-truth-conditional", but to the propositional representation, i.e., "conceptual."

(8) Regrettably, they said my paper was too long.

On the other hand, "implicature" is "non-truth conditional," but "procedural," which means that it identifies relations(premises and consequences) between the propositions deductively, as in so and after all. distinctions.

Wilson and Sperber (1993) classifies the utterance meaning into these three

(9) a. explicature: conceptual and truth-functional.

b. higher-level explicature: conceptual and non-truth-conditional.

c. implicature: procedural and non-truth-conditional.

Ifantidou-Trouki (1993) has taken this analysis further and suggested that adverbs are basically classified into (9a) and (9b), i.e., (9a): reporting adverbs such as allegedly and reportedly, and (9b): speech act adverbs such as frankly, confidentially and honestly, and manner adverbs such as unfortunately, sadly and regrettably.

Blakemore (1996) claims that IOW and that is should not be classified with expressions like so, after all and but, which encode procedures or constraints on interpretation. She says that IOW and that is should be analyzed as expressing higher-level explicature, like regrettably in (8). She calls these words "reformulation markers," because they communicate the information that something referred to by other words and the demonstrative that is identical with something. See "summarization" above. For example, IOW, in short and that is in (10) and (11) express B's beliefs by saying in other words.

(10) A: We will have to let her go.

B: In other words/In short, she's fired.

(11) A: The republicans disagreed with the legislation.

B: That is, the third party in the left-centre coalition disagreed with the legislation. (Blakemore (1996))

That is to say, (10) and (11) express the idea that the speaker summarizes/reformulates what the other has said, and believes the summarization to be true. Blakemore (1996: 340) rephrases these words into (12):

(12) The speaker believes that $\mathrm{P}$ is a faithful representation of a thought $\mathrm{Q}$, (P being the speaker's own words and Q being the other's words.) 
Blakemore (1996) gives an important evidence for her theory that these words express higher-level explicature:

(13) A: She said she no longer requires your services.

B: $\quad$ In other words, she said I'm fired.

A: $\quad$ That's not true. She didn't say that. (Blakemore (1996))

(14) A: Seriously, what a gorgeous tie.

B: $\quad$ That's not true. You're never serious. (Wilson and Sperber (1993))

According to Blakemore, the speaker B in (13) and A in (14) can be charged with untruthfulness. True, That's not true in (14B) denies A's word seriously. B does not commit his/herself to the tie's being gorgeous. This is because seriously in (14A) expresses conceptual idea, i.e., "it can be analyzed as contributing to propositions which have their own relevance - even though it doesn't necessarily contain the main point of the utterance as a whole.(Blakemore (1996: 336))" However, does this reason also explain the use of IOW and That's not true in (13)? Probably not. In (14), A can blame B for B's untruthfulness and unfaithfulness by saying differently, eg. That's not true. You're kidding. On the other hand, B in (13) cannot be charged with his/her unfaithfulness by A's words That's not true. That's not true in this case denies the whole utterance, i.e., whether or not she said B's fired, because A cannot go on the conversation like (13'), denying B's in other words alone.

(13') A: She said she no longer requires your services.

B: $\quad$ In other words, she said I'm fired.

A: \#That's not true. In fact, she said you're fired.(adapted from Blakemore(1996))

(13'A) is impossible, because either That's not true denies the whole clause of B, or That's not true cannot deny IOW alone just as it can deny seriously alone in (14B). For either reason, the contradiction in (13'A) shows that IOW cannot be classified with sentential adverbs, such as regrettably, seriously, etc. This is the point that Blakemore misses when she claims that IOW and other reformulation words, such as in that case, You mean...?, That means..., this/that being so, express higher-level explicatures. It is true that IOW has its linguistic meaning clearly and relates to the proposition/main clause just like seriously and regrettably. Seriously and regrettably can contribute to the truthfulness/faithfulness of the proposition, which is the main function of these words. However, IOW can contribute to the relationships between the ways of saying by the speaker and hearer, which means $I O W$ sometimes expresses/prefaces the speaker's own implicature as I will discuss below. In that case, IOW does not express the explicit way of saying the other's utterance, but instruct the hearer to interpret the utterance as an implicit meaning/implicature.

Such implicature-interpreting/inferential function of $I O W$ is evidenced when the implicature in $(6 \mathrm{~b})$ can be uttered, initiated by $I O W$.

(15) A: Did you get invited to the conference?

B: $\quad$ They said my paper was too long. 
A: In other words, you did not get invited to the conference. (adapted from Blakemore (1996))

Another suggestion that Blakemore made is that the use of $I O W$ and that is is acceptable only in a linguistic and discourse context, whereas so and after all, so-called discourse markers, can be used in non-linguistic context. Without some other words just before these words, IOW and that is cannot initiate the clause. However, this does not explain that $I O W$ and that is do not have procedural meaning. They have literal/linguistic meanings of their own. The use of the words in non-linguistic context shows that these words have procedural meanings, but not vice versa. Consider but in non-linguistic context. It can initiate the clause without saying anything before but, but the speaker already has in mind something contrary to his/her utterance.

Obviously, examples (1)-(4) function as expressing higher-level explicatures, because of their prototypical meanings. Clearly, the reformulation/summarization is not identical with the original at the level of linguistic form. The non-identification or resemblance in Relevance Theoretic terminology may have allowed $I O W$ to function inferentially by way of "grammaticalization." The process of grammaticalization is beyond the scope of this paper, but there is a cline/continuum within the pragmatic meaning of $I O W$. I will focus on the inferential use of $I O W$ below.

\section{Inferential function and interpretation of implicature}

\subsection{Inferential /interpretative process and background assumption.}

(1)-(4) are monologues, whereas inferential use of $I O W$ frequently occurs in a dialogue, as in (16). IOW may be used as "connective/link words" when answering or continuing a dialogue like (16a). The inferential function arises when it is assumed that the hearer does not understand the real meaning and it is necessary to explain that meaning. This is interpretation of the speaker's implicature by the hearer. "Inferential function" occurs when $I O W$ is interpreted as "That means." The hearer is replying, "From what you say I infer that..." or "You don't say so explicitly, but the conclusion I reach is that..." In (16b), there is a previous context for $I O W$, "From what he says, his wife refused to give him a divorce." From this context, it can be inferred that it is quite natural that he had asked his wife for a divorce before his wife's refusal, although the interlocutor did not say anything about a divorce.

(16) a. "I'm not very happy about what you're doing." "In other words, you don't trust me?" "I wouldn't quite say that." (from Manser (1983))

b. "And what were the circumstances?"

"First of all he said there must not be any publicity, and secondarily he said that his wife refused to give him a divorce."

"In other words he had asked his wife for a divorce and she had refused?"

"That is what he told me." (Sidney Sheldon, The Other Side of $\mathrm{t}$ ) Midnight) 
$I O W$ is a visible index of the hearer's implicature-interpretation process:

(17) A: I'm afraid there isn't much I can help you with.

B: $\quad$ In other words, you don't want to be bothered.

(from Quirk et al. (1972) )(Ball(1986))

Although the interpretation process of (17) is close to "conventional" use, in which the interpretation might be processed spontaneously, without any inference by the hearer, B guesses A's real intent indirectly from A's implicature, not directly from A's utterance, . For B to use $I O W$, B exploits background assumption or encyclopedic knowledge, implicating that A is busy now, or that A feels uneasy with B. If $p, q$ and $r$ stand for A's words, B's words and the implicature just explained respectively, then there is a sequential flow of consciousness or inferential process, $\mathrm{p} \rightarrow \mathrm{r} \rightarrow \mathrm{q}$.

To explain the implicature-interpretation process in more detail:

"Any member of her own family at this do?"

"Her husband."

"Her husband," said Dermot thoughtfully.

"Yes, but one always thinks that way," agreed his superior officer, "but the local man - Cornish, I think his name is - doesn't seem to think there's anything in that, although he does report that Baddock seemed ill at ease and nervous, but he agrees that respectable people often are like that when interviewed by the police. They appear to have been quite a devoted couple."

"In other words, the police there doesn't think it's their pigeon. Well, it ought to be interesting. I take it I'm going down there, sir?" (Agatha Christie, The Mirror Crack'd From Side To Side )

Dermot concludes that the local police think the case in question is beyond them. Where does this conclusion come from? The local police conclude that the husband of the murdered woman is not even a suspect in the murder. Therefore, Dermot is forced to infer (r)that there is nothing more to investigate. Dermot's background assumption that the husband of the murdered is usually a suspect, combined with the underlined clause in (18) creates $r$. "R" is a conflation of the speaker's background assumption and the interlocutor's spoken words. Such background assumption can be called up in the scenario of murder in (18).

$I O W$ can call up any background assumption, although whether A has already known B's knowledge is not really a matter of concern for B. IOW just enables B to infer what A wants to say. Whether A really intends to say what B thinks is not B's real concern. B just declares a conclusion. (19) shows how background assumption is not always shared by people in conversation:

(19) A: I shall be in Japan the last week of September.

B1: Oh, you'll miss the department meeting.

B2: In other words, you'll miss the department meeting.

B3: In other words, you're not going to be around to help me with my 
project.

B1's words amount only to logical inference - "If p, then q," with no intermediate background assumption. If B1 is in Japan the last week of September, then B2 must logically assumes that B1 will automatically miss the department meeting, because it is scheduled before B1 leaves here. However, B2 makes a different assumption, although the conclusion happens to be the same as B1's. B2 took for granted or had background assumption that A would attend the department meeting. So, when B2 heard A's words that A will go to Japan, B2 assumes that A will not be able to attend the meeting, contrary to what he already knows. In other words, $I O W$ in $\mathrm{B} 2$ leads to utter his own conclusion(q as in above). It is inferable from his own assumption( $\mathrm{r}$ as in above), which is derived from his own background assumption. B3 indicates background knowledge which is different from B2. Probably, A will help B3. Hearing A's words, B3 is shocked, disappointed, or angry at A's absence. $I O W$ uttered by $\mathrm{B} 2$ and $\mathrm{B} 3$ calls up background assumptions that they already had in mind. Such background assumptions of B2 and B3 are not always shared by A. However, from the answers of B2 and B3, A can also infer their contents, using A's background knowledge.

Even though background assumptions of speaker and hearer are different, the speaker can incorporate what the hearer has just said, using his own background assumption. Therefore, no misunderstanding occurs:

(20) A: I love Schubert's late piano sonatas.

B: In other words, you don't like the Beethoven sonatas?

$I O W$ in (20B) calls up a restricted set of background assumptions in which B has already admired the Beethoven sonatas. B assumes that A also admires Beethoven, but contrary to B's assumption, A declares admiration for Schubert. So, B feels A's words are critical, which is $\mathrm{r}$ above. B's background assumption becomes old, conflates A's new information with $\mathrm{r}$ and enables $I O W$ to create "p=q." Now, A understands that his declaring love for Schubert does provoke B's ill feelings towards him, because A knows that B uses $I O W$ for uttering B's own assumption.

A non-conventional, rather complicated use of $I O W$ is the following:

(21) A: I'm going to kill you.

B: In other words, you'd like it if I moved my car.

B's car obstructs A's car, so A gets infuriated at B, and utters the harsh words, "I'm going to kill you." A's real intent or implicature (r) is "I'm not happy if you don't move your car," or "Move your car." Beginning with $I O W$, B paraphrases "r" in his own words, "q." B's use of $I O W$ must assume that A implicates "r." B's background assumption - a person may utter harsh and terrible words in such a trivial matter - mitigates B's processing effort. If B has no knowledge that a person may exaggerate, A's words would be too much processing effort for B and B could not correctly interpret A's words. B's job is to process the flow of 
the dialogue, " $\mathrm{p} \rightarrow \mathrm{r} \rightarrow \mathrm{q}$."

At first glance, the next example might seem to draw no inference at all:
A: $\quad$ Sorry, I can't help you now.
B: $\quad$ In other words, you can't.

The implicature B can infer from A's words depends on the relation between A and B and the context in which A and B are engaged. For example, B can utter such implicature as "A is busy now," or "A dislikes B." However, B echoes A's words, leaving room for A to interpret B's real intent. B deliberately leaves the implicature from A's words intact, vague and indeterminate. The flow of consciousness is " $p \rightarrow r \rightarrow q$," as in (21B).

\subsection{Identification of " $r$ " inferential process, conversational implicature and Relevance Theory}

I do not intend to propose another outline of Relevance theory here. But I agree in principle with some central points which should be born in mind. A basic claim is that human cognitive activity is driven by the goal of maximizing relevance, i.e., "optimal relevance,"; that is to communicate in such a way as to derive as great a range of contextual effects (contextual implications, stregthenings and eliminations)as possible for the least effort. Of the three contextual effects, what concerns most in deriving implicature is the first effect: contextual implications. Deriving contextual implications and implicature in Relevance Theory are processed along the same line. I will briefly outline the derivation process of implicature, raise some problems and finally modify the process in dealing with implicature deriving connection words, such as $I O W$, that is and that means.

How can B infer A's implicature? Is the inferential process deductive and calculable? In Relevance Theory, in the exchange of Mary and Peter in (23), both implicated premise (24) and implicated conclusion (25), given through the deductive

\footnotetext{
${ }^{4}$ The implicature " $r$ " in the inferential process, " $p \rightarrow r=q$," is not so explicitly expressed, especially when interpreted poetically or as literary work. The following is from a famous American popular song. To my knowledge, and interestingly, the composer originally wanted to name the song "In Other Words."

Fly me to the moon and let me play among starts

Let me see what spring is like on Jupiter and Mars

In other words, hold my hand

In other words, darling, kiss me

Fill my heart with song and let me sing forever more

You are all I long for, all I worship and adore

In other words, please be true

In other words, I love you
}

(Composed and written by Bart Howard, Fly me to the Moon) Semantically and even pragmatically, there seems to be no relation between the linguistic contents of the first two lines and the second two lines including IOW. However, the inferential process is, if implicit, the same as (20)-(22) above. In the first two lines, "I" want to feel as if I were on the moon, playing among the stars and feeling the spring on Jupiter and Mars - in other words - "I" want to be as happy as can be. In order to make me feel so, what you do is hold my hand and kiss me. Even in the utterance by one person, $I O W$ works as a implicature deriving link word. 
process (26), seem to be considered old information.

(23) Mary: Do you ever talk to Charles?

Peter: I never talk to plagiarists.

(24) Charles is a plagiarist.

(25) Peter never talks to Charles.

(26) a. If Charles is a plagiarist, then Peter never talks to Charles.

b. Charles is a plagiarist.

c. $\quad \therefore \quad$ Peter never talks to Charles.

This process of implicature deduction gives rise to the question. Why should implicated conclusion be shared with the hearer as old information, as well as implicated premise? ${ }^{5}$ Does the hearer have to have implicated conclusion before hearing the speaker's words? If the hearer does not believe (24) is true, or does not have information about Charles's occupation, then what happens to this part of inferential process? Relevance Theory assumes that the speaker expects the hearer to construct implicature even if the hearer has no information at all. ${ }^{6}$ But why and how can a speaker convey such implicature and convey the speaker's intention to the hearer?

$I O W$ is a device that identifies the speaker's weak, indeterminate, ambiguous or not explicitly given implicature and indicates an explicit implicature in the same cognitive environment both speaker and hearer share. $I O W$ narrows the speaker's intended implicature on for the hearer, even if the speaker does not intend to give a specific meaning. In the dialogue of (23), to change "plagiarist" to "Charles" would identify implicature. Such a conversion device, the change of one word to another, is a comparatively easy operation in the deductive process.

On the other hand, to recognize the implicature as " $r$ " depends on the hearer's cognitive environment and the hearer sometimes reacts unexpectedly to the speaker's words. In example (27), Grete was surprised to hear the word fired. She actually did not want to use that word and intended to obscure the fact that she was forced to quit her job:

${ }^{5}$ In other words, the same problem is raised by Levinson (1987a), questioning whether or not the implicature in the Relevance Theoretic framework can be calculable, because he assumes that the implicated premise cannot be calculated.

${ }^{6}$ Nishiyama (1993: 224) also points out that a false implicated premise does not lead to a true implicated conclusion. Even if Mary knows Charles very well and believes that Charles is not a plagiarist at all, she must derive $(25=26 \mathrm{c})$ from two contradictory premises. One solution is that the premise introduced into the context is Peter's belief, not Mary's. Mary assumes that Peter believes that Charles is a plagiarist. Nishiyama considers this solution to be inadequate, because Mary cannot deduce (25) from Peter's words in (23) and a premise which is false for Mary. However, as discussed below, Mary receives the implicature which Peter invokes. She infers the same conclusion as if she were Peter when she hears the answer is no. What matters most to Mary is Peter's yes/no answer, not whether Charles is a plagiarist. Mary does not commit herself to the truth/falsity of the premise. She will correct Peter's belief immediately if she knows that Charles is not a plagiarist. 
"Well,"Grete replied, "it seems the Surgical Department here thinks I'm not cutting it - to coin a phrase. So they've offered someone else the senior residency and informed me that, though I was 'welcome to stay,' I wouldn't have a stipend and I'd have to slog my guts out as a volunteer."

"In other words, they fired you."

"Well,"Grete replied sarcastically, "you might say so. In fact, 'fired' was the only word they didn't use." (Erich Segal, Doctors)

(27) describes further that the implicature (the words summarized by the hearer), is derived from the implicated conclusion in the mutual cognitive environment of Grete and hearer. The hearer must have known and have had access to background knowledge that Grete's indirect expressions point to the word "fired". IOW in (27) shows that the conclusion or the implicature expressed as the explicit, spoken words must be stored beforehand in the hearer's cognitive environment. The implicated premises must share some part of the implicated conclusions. The work done by the hearer who utilizes $I O W$ is to construct a proper subset of the premise (already suggested by the speaker) and the conclusion (already stored in the mind of the hearer). IOW serves to pinpoint the words. Therefore, it must be admitted that there exists some kind of mutual knowledge between the speaker and hearer, if not identical in shape and content, even though Sperber and Wilson (1986: 15ff) doubt the existence of mutual knowledge if treated within the framework of the code model. IOW confirms that the speaker and the hearer share the same cognitive environment. A format deriving the deductive reasoning, "if $p$, then q," cannot stand on its own if there is no connection between $\mathrm{p}$ and q. Even in the seemingly detached conditional sentence, "If $1+$ $1=3$, the capital of Japan is Los Angeles," the fallacious cognitive connection between $p$ and q leads to the nonsensical implication of the whole sentence.

Implicated conclusion, implicature in general, in Relevance Theory is considered to be a newly derived assumption. True, the words used are new to the person hearing the sentence, but the implicature from these words derives from thought already stored in the cognitive knowledge of the same person who then utters the next sentence. New words uttered by one speaker are passed on to another, building on previously established common ground, and finally creating new knowledge/beliefs.

Sperber and Wilson (1986: 196) pursue the problem of strong/weak implicature or the indeterminacy, which "other pragmatists have tended to exclude from consideration." Sperber and Wilson argue that, in the dialogue of (28a) and (28b), an expected implicature, an implicated conclusion, strongly intended by Mary is (29b), whereas (30a)-(30f) are "not [implicatures] under the idealization (described above [a legitimate idealization to ignore indeterminacy])," (ibid., 198), in the sense of strong/determinate implicature. In a sense, (30a-f) are all weakly manifest.

(28) a. Peter: Would you drive a Mercedes?

b. Mary: I wouldn't drive ANY expensive car.

(29) a. A Mercedes is an expensive car. (implicated premise)

b. Mary wouldn't drive a Mercedes. (implicated conclusion)

(30) a. A Rolls Royce is an expensive car. (implicated premise) 
b. A Cadillac is an expensive car. (implicated premise)

c. Mary wouldn't drive a Rolls Royce. (implicated conclusion from (19a))

d. Mary wouldn't drive a Cadillac. (implicated conclusion from(19b))

e. People who refuse to drive expensive cars disapprove of displays of wealth. (implicated premise)

f. Mary disapproves of displays of wealth. (implicated conclusion from $(19 \mathrm{e}))$

The determinacy/indeterminacy of implicature, strong/weak implicatures, is in fact determined from the viewpoint of the speaker's intention, if explained by Relevance Theory. If Peter has, say, (30e) in mind strongly and exclusively, it is possible to continue a dialogue like (28c):

(28) c. Peter: In other words, you disapprove of displays of wealth.

Clearly, in (28c), Peter might run the risk of misunderstanding Mary's real intention. The speaker's intention is clearly distinguishable from the hearer's interpretation. In (27), the hearer has an idiosyncratic way of interpreting Grete's words. Grete heard the unexpected word fired from the hearer.

The implicatures, A's last responses in (31a) and (31b), with or without $I O W$, demonstrate a difference between implicature inferring processes of speaker and hearer:
a. A: If any of the students have failed I'll be in trouble.
B: $\quad$ I'm afraid some of them have.
A: I was afraid of that! (adapted from Carston (1995))
b. A: If any of the students have failed I'll be in trouble.
B: I'm afraid some of them have.
A: In other words, my method was wrong! (adapted from Carston (1995))

In (31a), the hearer responds to an implicature thought to be suggested by B. A does not use his own inferring process. A expresses fear that the students may have failed the examination. On the other hand, in (31b), one implicature suggested by B, "You may be in trouble," is introduced into A's own knowledge, so that A can utter his concern about himself. Note that since A has been worried about the students' examination results, the words initiated by $I O W$ are inferable not only from B's utterance, but also from A's own experiences stored in background knowledge. People live in little worlds of their own. From these world, $I O W$ invokes implicated conclusions.

The implicature the hearer draws is "abductive (given an utterance, hearers may relate it to a general maxim, and guess the speaker's intent)" (Hopper and Traugott (1993: 72)). A deductive process in the Relevance Theoretic framework is like putting one premise upon another and drawing a conclusion on top of the piled premises. It is possible for the hearer to reach the conversational goal, and then goes down to the details. (See Yamamoto (1996: 479-480) in more detail.) I claim here that the IOW abductively interprets the 
implicature the other person derives. In general, abduction is processed in the following way:

$$
\begin{aligned}
& \mathrm{p} \rightarrow \mathrm{q} \quad(\rightarrow \text { if..., then }) \\
& \mathrm{q} \\
& \therefore \quad \mathrm{p}
\end{aligned}
$$

Let $p$ be "it rained last night," q "the road is wet," then the first line of (32) is "if it rained last night, the road is wet." If the second line q is considered to be true, then $p$ must be true. However, p's being true cannot be logically deducted, because a truck might have sprinkled the road. Nevertheless, humans can regard $\mathrm{p}$ as having a reasonable/appropriate reason to be true, though $\mathrm{p}$ cannot be logically true. The implicature interpreting process of IOW arises from 2explicature" above in terms of grammaticalization. (See Hopper and Traugott (1993: 39-41, 69, 72) on inference and grammaticalization.) For example, in (31b), A already has an assumption that if any of the students fail, A will be in trouble, which means A's teaching method was wrong. A feels a strong concern about his own teaching method. Then A hears B's information that some of them failed the exam. A goes back to his first assumption, and then with IOW utters the implicature s/he interprets abductively .

Carston (1995: 236) does not think there should be any inclination in (31a) "to say that B's utterance implicates that not all of the students have failed." She argues against distinguishing between generalized and particularized implicatures. Not all derived from some is referred to as a generalized conversational implicature (hereafter GCI) by the Neo-Griceans, ${ }^{7}$ Levinson and Horn in particular. (See Levinson $(1983,1984,1987$ a, 1987b, 1989, 1995) and Horn (1984, 1989, 1992) in more detail.) Although the problematic distinction of these implicatures is not pursuable here, quantitative problems are relevant in the context where some implicates not all (GCI) - a contrast between some and all/others/the rest is at issue. (See also the second edition of Sperber and Wilson (1995: 276-278 (postface)) on how implicatures like not all from some do not always go through.) (33a-b) are GCIs and (34a) is a non-quantitative, (traditionally called) particularized implicature:

(33) a. Some of the people who speak through my pages are famous; others unknown. (Brown Corpus: D17) (from Sahlin 1979: 80)

b. In looking back over the volumes, it is possible to find errors of interpretations, some of which were not so evident at the time of writing. (Brown Corpus: G46) (ibid., 79)

Carston (1995: 236) rejects the notion of GCI and argues that what are supposedly GCIs are in fact "just one of many concept narrowings affecting the level of explicit content (what is said)." Whether the implication of not all from some is explicitly or implicitly said, what matters most is whether the hearer is able to understand what the speaker truly wants to say. The hearer must utilize inferential process in understanding the implied meaning,

\footnotetext{
${ }^{7}$ Neo-Griceans are mostly Levinson, Horn and some others, who exploit and develop Grice's (1975) "Quantity and Quality Maxims," into Q/I(R) implicatures. See also note 8.
} 
GCI or explicature (in Carston's and Relevance Theoretic terminology).

Regarding GCI/explicature from the speaker's point of view. the last responses of A in (20a) is only a reflex of B's implicature derived from B's own knowledge. Neither A nor B have access to a quantitative reading. What concerns them most, their contextual presupposition, is whether A will be in trouble, not whether some or all students have failed the examination. On the other hand, nothing but a some/all issue concerns the writer of (33a) and (33b), because (33a) is in the contrastive context (some vs. others) and (33b) contrasts the whole with a subset of errors of interpretation. People contrast things in the same set, not in a different set. In (33a), the writer considers the people of the same set and in $(33 \mathrm{~b})$ the same whole and subset of interpretations. Once a contrastive context begins, the opposite whole or subset is automatically suggested. Is this process not deductive like all other inferential processes deriving implicatures in the sense of the Relevance Theory? Roughly speaking, apart from offsetting some processing effort, contextual effects, especially contextual implications in Relevance Theory, give rise to common ground (Jucker and Smith (1996)) or contexts before the implicated conclusion is deduced. A contrast is one such context, which can derive a not all implication or explicit content. If not all appears only when contrasting quantitative concepts apply, if not all derived from some is context-dependent, as Carston (ibid., 235) says, then inferential process similar to ordinary (particularized) implicatures is required, at least on the speaker's side. There seems no distinction between what is explicated and what is implicated, at least in the way of inferential process.

Regarding the hearer, as explained in the discussion of (31a-b), IOW narrows the implicature suggested by the hearer (eg., A in the last line of (31b)). The narrowed implicature also occurs in GCIs. (34a) and (34b) are adapted from (31a) and (31b) respectively:

(34) a. A: If any of the students have failed I'll be in trouble.

B: I'm afraid some of them have.

A: ??I see. Not all of them have. I'm glad to hear that.

b. A: If any of the students have failed I'll be in trouble.

B: I'm afraid some of them have.

A: In other words, not all of them have. I'm glad to hear that.

For A to get out of trouble and to confirm that his teaching method was not wrong, A must make sure that at least some of the students, if not all, have passed the examination IOW in (34b) involves deriving a quantified implicature and speaking A's mind as B's hearer. However, as Carston (1995: 236) correctly predicts, in (34a), such quantification does not arise, because implicatures in general are the speaker's implication. Hearer $\mathrm{A}$ in the last line of (34a) does not react to his own beliefs/knowledge, but to what he assumes to be speaker $\mathrm{B}$ 's beliefs/knowledge. In the context of (34a), what is relevant to A in the first line is whether or not he will be in trouble, which depends on his students' examination results. $\mathrm{B}$, hearing A's concern, implicitly concludes that A may be in trouble by being indirect and saving face, saying that some students may not have passed the examination. B does not necessarily suggest that A's teaching method was wrong. For reasons of his own, A cannot carry on the conversation by violating coherence. Moreover, when A makes implicatures clear, he can only react to what B has in mind. A does not risk interrupting B's flow of 
consciousness without signaling to B that he is ready to use turn-taking connectives such as $I O W$ in (34) and That means in (35).

In (35), Mariner (played by Kevin Costner) beat the heroine, Helen, and cut her hair for making a bad attack against the enemy and damaging his boat, although she had already made an apology. Her adopted child, Enola, quarrels with what Mariner has done to her and snaps at him:

(35) Enola to Mariner: She said she was sorry. That means you're supposed to say something back. (from the transcript of Waterworld (A Kevin Reynolds film in 1995)).

In this scene, Enola's words took Mariner's breath away. He did not even hit on the idea that he must say something gentle when someone apologizes to him. That means also functions as a marker for uttering the speaker's own beliefs, rather than someone else's.

Although the implicatures uttered by B in (36) all depend on contexts, the words that follow $I O W$ or That means (i)all derive from Hearer B's own knowledge, (B introduces what seems to be implicated by A's words into his own knowledge), and (ii)by default interpretation, all are not of GCIs or Levinson's (1987b) Q- or I-implicatures ${ }^{8}$.Consider (36a-c):

a. A: $\quad$ Mary failed some of her exams.

B: In other words, I won't see her tomorrow.

${ }^{8}$ In Levinson (1987b: 67-68), (36a) and (36b) are given as Q-implicatures, and (36c) as an Iiimplicature. The two implicatures are to be inferred on the basis of the maxims/heuristics/principles in (i) and (ii) below (summarized by Carston (1995: 125-216):

(i) Q-implicatures (the negation of a semantically stronger proposition than the one expressed by what is said):
$(\mathrm{a})=(36 \mathrm{a})$
Mary failed some of her exams, <all, some>
$(b)=(36 b) \quad$ We scored three goals. $<\ldots$ four, three, two, one $>$
implicates: Mary didn't fail all of her exams.
imiplicates: We scored no more than three goals.
I-implicatures (semantically stronger than what is said):

(ii)

$(a)=(36 \mathrm{c}) \quad$ If you mow the lawn I'll give you $£ 10$.

implicates: If and only if you mow the lawn I'll give you $£ 10$.

See Carston's (1995) critical comment about Levinson (1987b). Carston (ibid., 236-237) also makes a brief comment on Levinson's M-implicature (M-heuristic: what's said in an abnormal (or marked) way isn't normal), saying that a marked, longer expression, for example, female sibling, derives effects that a normal word sister cannot obtain, offsetting the greater effort involved in processing the phrase. However, Carston's and the Relevance Theoretic account for M-implicature only adds effort-processing to the Levinson's original account. Carston says that female sibling requires more processing effort than sister, because the former is less frequently used, less accessible than the latter. Why is a longer, marked expression infrequent and less accessible? Is it not because such an expression requires more processing effort? Which reason comes first? This problem does not concern frequency of an expression, but the existence of a contrastive context. Implicature such as "I don't have normal sisterly relations with her" derived from female sibling does not arise unless the hearer strongly expects the word sister to be used. If, for some reason, abnormal sisterly relations are expressed in a normal, ordinary context, then sister becomes a marked word, requiring more processing effort. Frequency of an expression depends on which expression becomes de-contextualized, resulting in no gratuitous effort. See also Matsumoto (1995: 52-54) on the problem of a stronger statement requiring less processing effort, which is contrary to the general view of Relevance Theory. 

That means
b. A: We scored three goals.
B: $\quad$ In other words, you won./you lost.
That means
c. A: If you mow the lawn I'll give you $£ 10$.
B: In other words, get lost!/go away!
That means

\subsection{Failure of interpretation / inference}

As explained in (19), the answer without $I O W$ is enough to be interpreted like (19B1). IOW in (19B2) and (19B3) brings the implicature into the conversation, prefaces the inferential process, and also facilitates the coherence of the conversation.

It is difficult to define when and how the hearer fails to interpret or infer the speaker's implicature, even in a sentence with $I O W$. Primarily, $I O W$ is inappropriate if used to represent a completely misunderstood answer by the hearer:

(37) A: I'm afraid there isn't much I can help you with.

B: ?In other words, you need to be helped.

B misunderstands A's situation. Ordinarily, the implicature derived from A's words is "'m busy now," or "I can't help you now," etc. If A really wants to be helped like B says, A will not say that he cannot help B. A's words miss the point. One rather unusual situation makes it possible to carry on the conversation smoothly. When B sees A with hands full of his baggages, A describes that he cannot help B. Otherwise, B doubts A's ability and insults A, implying that $\mathrm{A}$ is disabled. Therefore it is A who needs help.

If $\mathrm{B}$ draws an inference contrary to (17) above, he can respond to A, beginning with $I O W$, but A cannot understand what B really wants to say. The conversation does not make sense at all. (38) is also a case in which B completely misunderstands what A wants to say:

(38) A: I'm afraid there isn't much I can help you with.

B: $\quad$ *In other words, you want to be bothered.

B's utterance is unclear unless $I O W$ conflates the implicature derived from A's words with B's background assumption.

We assume that the flow of consciousness, the inferential process of $I O W$, is like (39):

$$
\mathrm{p} \rightarrow \mathrm{r} \text {; in other words } \mathrm{r}=\mathrm{q} .(\rightarrow \text { : implicate })
$$

(40) is an example that gives no information at all. In (28), A has already described the implicature "r." "Because I'm busy" is derived from "I can't help you now", so there is no use echoing A's implicature. The information reduces to zero:

(40) A: Sorry, I can't help you now, because I'm busy. 
B: $\quad$ *In other words, you're busy.

On the contrary, in (41), a reply without $I O W$ fails to interpret A's implicature. Instead $I O W$ is needed:

(41) A: Isn't it a beautiful day?

B1: What? ?You do not want to be here with me?

B2: What? In other words, you do not want to be here with me?

As in (19), inferential process of implicature usually works when a hearer can infer what another person wants to say. In (41B1), it is hard to interpret A's implicature unless A and $\mathrm{B}$ have already promised to work together indoors. After hearing B1's utterance, A is surprised that his words were interpreted contrary to his intention. A may have uttered his words as an everyday greeting, and he will remember the promise to work together, combining the promise with his background assumption. If there was no promise, A cannot understand B1's real intent. IOW in (41B2) can order that the cognitive environment of A and B2, their background assumptions, be identical. A is forced to interpret B2's intention after B2 derives A's unintended implicature from A's words. (41B1) and (41B2) show how B's identification of A's implicature works.

\subsection{IOW vs. $s o^{9}$}

So also has inferential function. The difference of inferential functions between so and IOW sheds light on how differently speaker and hearer infer one conclusion from each other's utterance. Ball (1986) and van Dijk (1977) state that so describes a logical consequence inferred from or resulting from the first proposition. Blakemore (1987: 85-91, 1988) explains that so expresses an inferential connection between propositions. So introduces a proposition deducible from a preceding proposition. This second proposition is seen as a contextual implication of the first. So, in Relevance Theory and Blakemore's account, constrains the hearer's choice of words for its interpretation ${ }^{10}$. So is a marker of prefacing and constraining the relevance of two propositions. Unlike so, IOW does not constrain the words the speaker/hearer chooses to be adequate, but identifies and pinpoints the adequate

${ }^{9}$ Other link words such as in that case, that is show different distribution from $I O W$. See the following:

(i)

A: $\quad$ I'm afraid there isn't much I can help you with.

B: $\quad\{$ In that case / $(*)$ In other words $\}$ I shall have to ask someone else.

(ii) They took refreshments, \{that is $/ *$ in other words $\}$, sandwiches, coffee, beer, fruit juice, and chocolate.

In that case in (i) connects the previous utterance and its resultant conclusion. Those who accept IOW may take A's words as implying that A is busy now and conclude that the implicature directly leads to asking someone else. This is a rather roundabout way of saying for $I O W$. That is (ii) allows examples or samples to be given open-endedly. $I O W$ is a closed-ended way of giving examples. One of my informants says that (ii) is read as if they took the same refreshments every day, if $I O W$ is acceptable.

\footnotetext{
10 "Constrains" means that $s o$ can narrow the inferable implicatures to one so that it "constrains" the relevance of the sentence in question. (Blakemore $(1987,1988)$ )
} 
implicature derived from preceding utterance or from weak implicatures the preceding utterance seemed to convey.

Like $s o, I O W$ also expresses inferential function. But, unlike $s o, I O W$ is not always associated with a logical consequence. Compare, for example, the acceptable use of $s o$ with the unacceptable use of $I O W$ in (42). Asterisks between parentheses indicate that some people accept $I O W$ :

(42) a. There was $\$ 5$ in my wallet. $\left\{\right.$ So $/\left(^{*}\right)$ In other words $\}$ he hadn't spent all the money.

b. She's your teacher. $\{$ So / (*)In other words $\}$ you must respect her. (adapted from Blakemore (1988)

In (42a), not spending all the money must be a logical consequence inferred from the fact that there is only $\$ 5$ in the wallet. The preceding utterances in (42a) and (42b) are too vague for $I O W$ to identify the implicature derived from the first proposition and to specify that the two propositions are equivalent. Even for those who accept $I O W$ in $(42 \mathrm{a}), I O W$ may sound "mildly insulting," implying that the hearer cannot do arithmetic at all. Therefore, IOW in both sentences of (42) is basically unacceptable.

(42) suggests that the effect of $I O W$ in an utterance is to avoid vagueness or indeterminacy of the first proposition that usually identifies and limits intended implicatures. So, on the other hand, has no connection with implicature inferring process. Rather, it only expresses a relation of logical consequence even if the inferential connection is determined by a similar deductive process.

In (43), it is very difficult to have only one type of assumption, based on "the horn makes funny noises":

(43) Playing the French horn.

A: $\quad$ Anyway, the horn makes funny noises. $\{$ So / *In other words $\}$, it's a treacherous instrument isn't it? It's something that is very hard for you to control. Why is that? Too much spit, or what?

B: I'm glad you've used the term. Because it's not difficult. It is treacherous. So are the players, of course. But that's another story. (adapted from Ball (1986))

If $I O W$ were acceptable in (43), it would be impossible to draw from the first sentence some other implicatures which could be rephrased into the second sentence.

So does not only express inferential connection, but also is interpreted as a causal consequence of the first proposition, cause-effect relation on the state of affairs. If this cause-effect so is replaced by $I O W$, the acceptabilities depend on whether the first sentence can give rise to the implicature directly leading to the second sentence. Compare the acceptable and unacceptable uses of $I O W$ in (32):

(44) a. Tom ate the condemned meat. $\{$ So $/ *$ In other words $\}$ he felt ill.

b. $\quad$ Bill insulted Mary. $\{$ So / In other words $\}$ she left. (adapted from Blakemore (1988)) 
The difference between so and $I O W$ in (44a) is provided by rather familiar situations in which the cause-effect interpretation is more easily understood against background knowledge. Eating the condemned meat directly causes Tom to feel ill in the easily understood context. However, in (44b), the cause-effect relation between insulting Mary and her leaving home is not the only possible interpretation. Consider another scenario, in which Bill insulted Mary because she left home. Mary's leaving home proves that she is so cowardly that she deserves to be insulted. $I O W$ expresses the situation where the first and second sentences are equally described, and equally relevant to the speaker and hearer. The speaker of (32b) uses the words insulting and leaving on the same descriptive level.

\section{Conclusion}

An utterance " $p$, in other words, $q$ " has an inferential process (hearer's interpretive process) " $\mathrm{p} \rightarrow \mathrm{r}$; in other words $\mathrm{r}=\mathrm{q}$," as well as a prototypical use of IOW in its explicit aspect of the utterance. One use of $I O W$ instructs the hearer to establish an inferential connection, so that $I O W$ can identify and limit the implicatures derived from preceding utterance. Once the speaker's intended implicature is introduced into the hearer's knowledge, the hearer interprets the speaker's implicature and, using $I O W$, draws implicature. Speaker's implicature may differ from hearer's. The hearer may run the risk of misunderstanding the speaker's real intention. However, the conversation does not lose its coherence, because IOW confirms that the speaker and hearer share the same cognitive environment. Most naturally, IOW in the dialogue of the two people is used to tell the one person to abductively interpret the implicature the other person might have conveyed.

In addition to the function of equalizing " $r$ " with "q", IOW instructs the speaker hearing the hearer's interpretation to recognize that the hearer's implicature is derived from or based on the hearer's background assumptions. Quite often, the hearer's background assumptions are built on the speaker's background assumptions, so that the same cognitive environment shared by the speaker and hearer is confirmed by IOW.

So also establishes an inferential connection, but it is unconnected with the implicature inferential process.

\section{References}

Ball, W.J. (ed.) (1986) Dictionary of link words in English discourse. London: Macmillan.

Blakemore, Diane (1987) Semantic constraints on relevance. Oxford: Basil Blackwell.

Blakemore, Diane (1988) So as a constraint on relevance. In R.M. Kempson (ed.), Mental representations: The interface between language and reality. Cambridge: Cambridge University Press, pp. 183-195.

Blakemore, Diane (1996) Are apposition markers discourse markers? Journal of Linguistics 32: 325-347.

Carston, Robyn (1988a) Implicature, explicature and truth-theoretic semantics. In R. Kempson (ed.), Mental representations: The interface between language and reality. Cambridge: Cambridge University Press, pp. 155-181. 
Carston, Robyn (1988b) Language and cognition. In F.J. Newmeyer (ed.), Linguistics: The Cambridge survey III language: Psychological and biological aspects. Cambridge: Cambridge University Press, pp. 38-68.

Carston, Robyn (1995) Quantity maxims and generalized implicature. Lingua 96: 213-244.

Dijk, Teun A. van (1979) Pragmatic connectives. Journal of Pragmatics 3: 447-456.

Grice, H. Paul (1975) Logic and conversation. In P. Cole \& J.L. Morgan (eds.), Syntax and semantics, vol. 3: Speech acts. New York: Academic Press, pp. 41-58.

Hopper, Paul J. and Elizabeth Closs Traugott (1993) Grammaticalization. Cambridge: Cambridge University Press.

Horn, Laurence (1984): Q-based and R-based implicature. In D. Schiffrin (ed.), Meaning, form and use in context (GURT '84). Washington, DC: Georgetown University Press, pp. 11-42.

Horn, Laurence (1989) A natural history of negation. Chicago: Chicago University Press.

Horn, Laurence (1992) The said and the unsaid. Ohio State University Working Papers in Linguistics 40: 163-192.

Ifantidou-Trouki, Elly (1993) Sentential adverbs and relevance. Lingua 90: 69-90.

Jucker, Andreas H. and Sara W. Smith (1996) Explicit and implicit ways of enhancing common ground in conversation. Pragmatics 6: 1-18.

Levinson, Stephen C. (1983) Pragmatics. Cambridge: Cambridge University Press.

Levinson, Stephen C. (1987a) Implicature explicated? Behavioral and Brain Sciences 10: 722-723.

Levinson, Stephen C. (1987b) Minimization and conversational inference. In J. Verchueren and M. Bertuccelli-Papi (eds.), The pragmatic perspective. Amsterdam: Benjamins, pp. 61-129.

Levinson, Stephen C. (1989) A review of Relevance. Journal of Linguistics 25: 455-472.

Levinson, Stephen C. (1995) Three levels of meaning. In F.R. Palmer (ed.), Grammar and meaning: Essays in honour of Sir John Lyons. Cambridge: Cambridge University Press, pp. 90-115.

Manser, M.H. (ed.) (1983) A dictionary of everyday idioms. London: Macmillan.

Matsumoto, Yo (1995) The conversational condition on Horn scales. Linguistics \& Philosophy 18: 21-60.

Morgan, Jerry L. (1987) Two types of convention in indirect speech acts. In P. Cole (ed.), Syntax and semantics vol. 9: pragmatics. New York: Academic Press, pp. 261-280.

Nishiyama, Yuji (1993) Kontekisuto koka to kanrensei: kanrenseiriron no mondaiten (Contextual effects and relevance: Problems of Relevance Theory). Eigoseinen 136: 222-224.

Recanati, Francois (1989) The pragmatics of what is said. Mind and Language 4: 295-329.

Quirk, Randolph, Sidney Greenbaum, Geoffrey Leech and Jan Svartvik (1972) A grammar of contemporary English. London: Longman.

Quirk, Randolph, Sidney Greenbaum, Geoffrey Leech and Jan Svartvik (1985) A comprehensive grammar of the English language. London: Longman. 
Sahlin, Elisabeth (1979) "Some" and "any" in spoken and written English. Stockholm: Almqvist \& Wiksell. Schiffrin, Deborah (1987) Discourse markers. Cambridge: Cambridge university Press.

Sperber, Dan and Deirdre Wilson (1986) Relevance: Communication and cognition. Oxford: Basil Blackwell.

Sperber, Dan and Deirdre Wilson (1995) Relevance: Communication and cognition. (Second edition). Oxford: Basil Blackwell.

Tanaka, Hiroaki (1995) Implicature of not...until. English linguistics 12: 272-278.

Wilson, Deirdre and Dan Sperber (1986) Inference and implicature. In C. Travis, (ed.) Meaning and interpretation. Oxford: Basil Blackwell, pp. 45-75. Also in S. Davis (ed.), Pragmatics: A reader. Oxford: Oxford University Press, pp. 377-393.

Wilson, Deirdre and Dan Sperber (1993) Linguistic form and relevance. Lingua 90: 1-25.

Yamamoto, Eiichi (1996) Jouhoukouzou ni miru kanrensei no yakuwari (The role of Relevance from the viewpoint of information structure). In Tamotsu Koizumi (ed.), Gengotankyu no ryouiki (A domain of linguistic investigation). Tokyo: Daigakushorin, pp. 477-485. 